\title{
Mathematical Construction Through Conceptualization of Natural and Socio-Cultural Objects in the NKRI Border Area
}

\author{
Sam M. Salajang*, Patricia Vivi J. Runtu \\ Mathematics Department \\ Universitas Negeri Manado \\ Tondano, Indonesia \\ *santjesalajang@unima.ac.id,vivi_runtu@yahoo.com
}

\begin{abstract}
This article presents the results of research on the construction of mathematical study objects through the conceptualization of natural and social-crocodile objects in elementary mathematics learning in Makalehi Island and Marore Island, which are included in the border regions of the Republic of Indonesia. Mathematical conceptualization begins with the procedure of identifying, inventorying, and classifying natural objects, socio-cultural and formulating their interactions in the form of children's games and daily activities. The following process is the mathematical conceptualization of these objects through symbolization, quantization, concept or network of mathematical concepts and procedures, as well as synchronizing with mathematics learning materials in class. The results of the study identified several elements of natural and socio-cultural objects, which are the background of children's games and daily activities, which support elementary mathematics learning. The "bridge" of elementary school mathematics construction can use an inventory of some children's games and activities. A theoretical formulation as mathematical construction can be a hypothesis to be classified as good in terms of the meaning of symbols, quantization, the formation of concepts, or networks of elementary mathematics concepts. Theoretically, mathematical conceptualization like this has the potential to enable students to learn mathematics with ideal activities.
\end{abstract}

Keywords: natural objects, socio-cultural objects, synchronization, conceptualization, construction

\section{INTRODUCTION}

This article contains the results of research on mathematical conceptualization through games and daily activities of children who are on the island of Makalehi, Siau-TagulandangBiaro Islands District, and in Marore Sangihe Islands District. The area, which is part of the NKRI border area, consists of several small islands, including those that are inhabited and have elementary, junior high, and high schools education facilities such as Makalehi Island and Marore Island. According to Mercer [1], small islands have special characteristics related to biophysical, socio-cultural, and economic conditions. Ecologically, small islands are vulnerable to global changes such as climate change [2], sea-level rise [3], or interactions between global pressures and local dynamics that contribute to increased environmental vulnerability [4]. On the other hand, small islands have socio-cultural power that develops in response to various pressures or difficulties of natural factors and external socio-cultural influences. The natural and socio-cultural conditions of the community determine the forms of children's daily activities and the ways of children's play.

The problem of access to education in Marore Sub district and Makalehi Island is still a serious problem among others related to the availability and implementation of teacher assignments, learning materials, support, and parents/community views on learning. Learning materials, which are prepared nationally, only depend on textbooks; teachers have not been creative in utilizing learning resources from the surrounding environment [5,6]. Utilization of the environment (natural and socio-cultural) as a source of learning on small islands has strategic values such as (1) increasing knowledge, skills and positive benefits of the natural and sociocultural potential of the community, (2) increasing mastery of the relationship between the concept of learning with the reality of life around children, (3) developing participatory community activities for the implementation of education. Types of games and students' daily lives are part of the utilization of the environment for learning, which has a strong influence on learning motivation because it answers students' needs and problems.

The identification, inventory, and classification of mathematical learning objects about games and children's daily life is part of the mathematics learning resource mapping strategy that is established as a strategic plan for mathematics learning research at Manado State University. This mapping is the basis for the development of mathematics learning research for various levels of education so that it becomes a means to apply educational services by Unima. Mathematical conceptualization innovations from children's games and daily lives and the design and implementation of their learning can be developed and adapted in other areas as an expansion and development of mathematics learning research. 
The target of this research is to produce mathematics learning products sourced from the natural and socio-cultural environment by the community and the design and implementation of models that can be followed up by the teacher and the community. The specific purpose of the research is to identify, inventory, and classify learning objects. The forms of learning objects are children's play and children's daily activities to conceptualize mathematics to become mathematics learning materials for elementary students, interactive between learning in class and outside the classroom. A group of people who have the same relative characteristics of both the natural environment and socio-cultural conditions inhabits a small island. The natural and socio-cultural elements on the small islands are unique and are a unity that has developed through a long process from generation to generation. Small islands have special characteristics related to biophysical, socio-cultural, and economic conditions [1]. The learning design on the small island must be following the characteristics of the small island, which includes natural and socio-cultural characteristics as a whole, and involves all components of learning, in this case, are teachers, parents, and the community. Utilization of the surrounding environment as a thematic learning source must cover all components of the environment, both natural, socio-cultural as well as naturalsocio-cultural interactions.

Thematic learning about the environment will increase (1) the actual knowledge and attitudes towards the utilization of natural resources, (2) the relationship between experience and what is learned, [5], (3) the motivation to obtain information and exchange ideas [7], (4) the collaborative activities among students, and between students and parents [5,8], (5) the learning process across ages or education levels [9], (6) the group interactions with different socio-cultural backgrounds, (7) the problem-solving skills and critical thinking [10].

Mathematics is a subject taught since the first grade of elementary school and gradually increases at the level of class and subsequent education. Mathematics, as connecting science to other fields of study, has variables and relationships between variables. It is expressed quantitatively and using symbols. Mathematics is universal (as a universal language) because it is not conditioned by cultural differences [11-13]. Favilli [11] believes that mathematics is the most universal set of concepts and ideas. Even though it is universal, special conditions make mathematics diffuse and patterned into special [14]. In particular contexts, mathematics can explain the universal properties of natural and socio-cultural phenomena. Universal nature provides advantages in explaining, conducting studies/analysis based on mathematical principles and procedures.

According to Broaler [15], students want to learn mathematics as a whole with the environment. Mathematical context can be in the form of natural, socio-cultural, economic, industrial, etc. Mathematical contextualization in science is related to dimensions, size, rate of change, spatial distribution, etc. In the socio-cultural field, increasingly "ethno mathematics" is a group of ideas that pay attention to the history of mathematics, the roots of mathematical culture, mathematics in everyday life, and mathematics education [16]. Favilli and Tintori [17] suggested that ethno mathematics is a research program on the history and philosophy of mathematics that has pedagogical implications, focusing art and techniques on providing explanations, understanding, and copying differences in socio-cultural environments. An interesting mathematical assignment will encourage students to develop ideas to study mathematics [18], to increase efforts to understand the relationship of context with mathematical concepts [19], to link-local settings with global/external based on mathematical concepts [20], and to solve problems [21-23]. The characteristics of small islands indicate that inherently, knowledge, skills, and mathematical values are inherent or constitute a unity with the socio-cultural community and the community's response to the conditions of the natural environment. The form of games and daily activities of students (interactions with families, helping parents, etc.) are special forms of objects as well as interesting learning resources because they are the needs of students. The principles of developing mathematical material and learning activities that utilize the environment around students, such as the relevance of student experience and needs, are very strongly represented through the form of games and daily student activities. Mathematical conceptualization through games and activities of children's everyday life is the basis for the development of mathematics learning by utilizing learning resources from the surrounding environment. Understanding the mathematical conceptualization here is the formulation of the forms and procedures of children's games and daily activities in the way of symbols, relationships, comparisons, and quantities (quantitative) mathematical. Conceptualization needs to involve various parties: experts, teachers, parents, and the community. Knowledge, skills, and values in the community must be entered and strengthened through instructional materials and learning targets.

\section{MethodS}

In this research, the researcher has some stages conducted as follow:

\section{A. Coordination stage}

Coordination with local governments (Sitaro and Sangihe) for secondary data collection, conducting surveys, namely identification of locations, natural objects, and obtaining resource persons for socio-cultural data.

\section{B. Identification - Inventory - Classification Stage}

These procedures are applied to the objects of natural elements, socio-cultural elements that form the basis of children's play, and daily activities. Based on the assumption that the environmental conditions of the natural and sociocultural elements formed, developed, or adapted to the form of children's play and daily activities, an identification procedure is applied. The results of the identification of natural and sociocultural backgrounds can be used to reconstruct the forms of games that have been lost or have begun to be abandoned, providing reinforcement and development following natural 


\section{RESULTS AND DISCUSSION}

and socio-cultural conditions. This process will generate or strengthen knowledge, skills, and values of mathematics learning through direct experience, both designed as learning activities and learning initiatives while playing or doing activities. Strengthening this background is directed in the framework of building national attitudes and behavior so that it will enhance the integrity of the young generation in the border regions of the Republic of Indonesia. Based on the identification results, inventory and classification are carried out according to mathematical study objects and formulated reinforcement, development or adaptation of activities and activities to be more contributory to the improvement of mathematical knowledge, skills, and values. The indicators to measure research performance are: (a) the number of forms of play and activities of children identified, inventoried and classified according to mathematical concepts and procedures, (b) the amount of strengthening of natural elements that still exist from the form of children's play and activities, (c) the number of natural reinforcement elements that still exist from the kind of children's games and activities, (d) the many reconstruction/integration of natural and socio-cultural elements in the form of games and activities that strengthen mathematical knowledge, skills and values, (e) the role and initiative of the community to provide information/input as well as mathematics learning development initiatives.

\section{Conceptualization Stage}

This stage consists of symbolization, quantization, conceptnetworking, mathematical procedures synchronized with learning material in class. The process will produce an interactive mathematics learning design space between learning activities in the classroom and outside the classroom. Conceptualization results can be a reference for the provision of learning assignments in schools that students do outside the classroom or outside of school with the assistance of parents and the community. The results of this conceptualization will also direct and encourage children's initiative to learn while playing or when doing daily activities. The indicators of research performance are (a) the number of forms of play and activities of children which are fully described in terms of concept/variable relationships in the way of mathematical symbols, (b) the number of forms of games and activities that are formulated in the form of mathematical procedures, (c) the number of alternative mathematical methods developed, relevant to the game process and student activities, (d) the participation and ability of teachers in mathematical conceptualization. Data obtained are product evaluations (including teacher and community assessment), interviews with teachers, parents, and the community. Data analysis to evaluate research performance used quantitative analysis (including percentages) and qualitative (socio-cultural search aspects). The background of children's activities and play as data on natural and socio-cultural conditions are used to reconstruct and strengthen mathematical knowledge, skills, and foster life values in the national dimension.
Presented below are natural objects and socio-cultural objects, which are the background of children's games and daily activities (table 1).

TABLE I. NATURAL AND SOCIO-CULTURAL OBJECTS AS A BACKGROUND OF CHILDREN'S GAMES AND DAILY ACTIVITIES

\begin{tabular}{|l|l|l|}
\hline \multicolumn{1}{|c|}{$\begin{array}{c}\text { Children's Games / } \\
\text { Activities }\end{array}$} & Natural Objects & \multicolumn{1}{|c|}{ Social Objects } \\
\hline Me 'kakembuni game & Hills & $\begin{array}{l}\text { Community } \\
\text { activities in the } \\
\text { garden }\end{array}$ \\
\hline Me 'dalrutang game & Rocks & Eat the game \\
\hline Sumelung game & Little forest & Togetherness \\
\hline Memiti' activity & Bamboo & Go to sea \\
\hline $\begin{array}{l}\text { The activity of watching } \\
\text { tamo traditional cake } \\
\text { cutting }\end{array}$ & Field/home page & Community habits \\
\hline Salo dance activity & $\begin{array}{l}\text { Sea, river, fish, } \\
\text { forest, animals }\end{array}$ & Salo dance \\
\hline
\end{tabular}

Next is given an example of mathematical conceptualization in some elementary school games, namely studying the mathematical construction of content, activity, and objective in 3 (three) children's games and 3 (three) daily activities for students.

\section{A. Me'kakembuni Game}

- Game content: Two or more people run this Game by choosing a yard or field near a small forest. Usually more crowded if followed by many participants. A group of children agreed to determine who served as a Postal Guard, and other children are hiding. The deal is done by lottery or by suten. The agreement is that the furthest distance from the post was to hide.

- Mathematical constructions in the game content include the concept of integers and the concept of a circle's radius.

- Game activity: The game begins with the children running around looking for a hiding place, while the Postal Guard must close his eyes so that everyone does not know the hiding place. After passing a certain amount of time to hide, usually 2-3 minutes, the Postal Guard starts operating in search of targets until they found all bias. The intended target is his friend, who is hiding. If the Postal Guard found someone, then he must say the name and immediately run to the Guardhouse to touch it. If the friend who precedes touches the Guard Post, then the Game starts again with the same child as the Guard Post.

- Mathematical construction in the game activity includes the concept of distance and speed.

- Game objective: Foster togetherness and honesty among children.

- Mathematical construction in the game objectives includes the concepts of distance and speed. 
- Mathematical construction in the activity content includes straight-line, size concept, angle concept.

- Activity: Individuals or groups of children wearing swimming goggles then diving while observing or rather choosing fish to be "piti". After passing a certain time, they stop and count the results of each. If there are followers who also dive with the task of holding the "sasusu kina", then they divide according to mutual willingness.

- Mathematical construction in the activity includes the accuracy of the target, the concept of time, the concept of division.

- Mathematical construction in the game activity include the concepts of integers, distance, and speed.

- Game objective: the last child who is not trapped determine as the champion.

- Mathematical construction in the game objectives includes the concept of integers, comparison, and ranking.

\section{Me 'dalrutang Game}

- Game content: A group of children equips themselves with 'lutang' and 'panggelu' as much as possible to play. If there are many participants, then it is usually divided into two groups facing each other as "opponents". Then they play 'me' dalrutang' until one party gives up or both parties agree to stop playing.

- Mathematical construction in the game content includes the concept of numbers, sets, and division.

- Game activity: The game consists of two teams, for instance, and each team member has a certain number of "bullets" (for example, 20 items). The debt starts within a certain time. Each team member reports how many bullets were hit, was missed, and was left to each commander after completing the debts. Then each team can claim to be the winner, with the agreed indicators.

- Mathematical construction in the game activity includes the concept of comparison, integers, integer operations, fractions, and fraction operations.

- Mathematical construction in the game objectives includes the concepts of comparison, integer, fraction and fraction operations.

\section{Me miti' Activity}

- Activity content: The Game is carried out by individuals or groups of children by diving in the sea while carrying equipment. The equipment carried was swimming goggles, "papiti' "(a type of fish archer), and" sasusu' quinine". If an adult does it, then this activity can be classified as a type of livelihood, but for children, this is a game because it is done with sheer pleasure motivation.
- Activity objective: The activity aims to get fun and also get fish. There is a kind of competition among children to win the championship in terms of the number of shots.

- Mathematical construction in the activity objective includes the concept of comparison, data collection, data processing, mode, mean, and median.

\section{E. Tamo Indigenous Cake Slaughtering Activities}

- Activity content: Cultural rituals. They taught about it at school. At special events such as weddings, cultural celebrations like Tulrude, they do Tamo cuts. After the host was invited, the Tamo cutter officer who wore the traditional clothing of Sangihe came forward and held a knife, but had not yet done the cutting.

- Mathematical construction in the activity content includes the concept of fraction numbers and the division of fractions

- Activity: Children watch this traditional ritual. It is usually preceded by a speech/elder in Sasahara language (Sangihe-doeloe language) spoken in an interesting loud voice. Even though it is difficult to pronounce, but the language is understood by most of the Sangihe community today. After giving the clergy, the prayer continued with the deduction of Tamo as well as powerful words containing profound meaning. Furthermore, Tamo pieces are distributed to all attendees, but the first to get a share is the bride if a wedding party or the head of government if the Tulrude event.

- Mathematical construction in the activity includes the concept of fractions and the division of fractions.

- Activity objective: For children who watch, the goal is to get enlightenment about the customs/culture of the past beloved area.

- Mathematical construction in the activity objectives includes the concept of fractions and the division of fractions. 
Number 0462 / UN41.09 / TU / 2018 with Agreement / Contract Number 072 / SP2H / LT / DRPM / 2018.

\section{REFERENCES}

dance that can be performed by elementary schoo children, as shown above. Solo or groups can play this dance. This war dance is an expression of the ancestor's pride who maintain the existence of the island community peaceful. They were prone to crime; such as pirates or as pirates who occasionally landed on a private island.

- The mathematical constructs in the activity content includes the set concepts, integers, and integration operations.

- Activity: Traditional music is sounded in conjunction with loud commands that encourage the Salo Dance players to make movements with fierce facial expressions and make loud voices. If other players act as opponents, then the player and opponent face to face with gestures and facial expressions as if challenging each other fighting. After the music ends, usually 5-10 minutes, the dance ends, and other dancers replaced.

- Mathematical construction in the activity include the set concepts, integers and integration operations, and data concepts

- Activity objective: Maintaining the culture of ancestors and fostering the attitude of a knight.

- Mathematical construction in activity objectives includes the set concepts, integers and integration operations, and data concepts.

\section{CONCLUSION}

The conclusions of this study are as follows. Many daily children's games and activities that can be used to construct mathematical study objects through mathematical conceptualization that can be used as a means of elementary school mathematics learning. Through each Game or form of daily children's activities, the objective of mathematical study can be constructed through the mathematical conceptualization of more than one object of mathematical research. In elementary mathematics learning, teachers can use certain games to teach more than one objective of mathematical study. Natural and socio-cultural objects support the re-actualization of children's play and children's daily activities in the border regions of the Republic of Indonesia to serve as a bridge for mathematics learning. In general, children in the border regions of the Republic of Indonesia, especially those on Makalehi Island, which is one of the outer islands in the North of the Republic of Indonesia, have Indonesian habits, but still need more touch so that their nationalities is more solid as citizens of the Republic of Indonesia.

\section{ACKNOWLEDGMENT}

Thank you to the Directorate General of Higher Education, in this case, the Directorate of Research and Community Service for providing funding for this research with Decree
[1] J. Mercer, D. Dominey-Howes, I. Kelman and K. and Lloyd, "The potential for combining indigenous and western knowledge in reducing vulnerability to environmental hazards in small island developing states," Environmental Hazards, vol. 7, pp. 245-256, 2007.

[2] M. Van Aalst, "The Impacts of Climate Change on the Risk of Natural Disasters," Disasters, vol. 30, no. 1, pp. 5-18, 2006.

[3] K.S. Rodolfo and F.P. Siringan, "Global Sea-Level Rise Is Recognized, But Flooding from Anthropogenic Land Subsidence Is Ignored Around Northern Manila Bay," Philippines. Disasters, vol. 30, no. 1, pp. 118139, 2006.

[4] M. Pelling and J. Uitto, "Small Island Developing States: Natural Disaster Vulnerability and Global Change," Environmental Hazards, vol. 3, pp. 49-62, 2001.

[5] C.s. Medellu, Lumingkewas and J.F. Walangitan, "Democratization of Learning through Thematic Assignment," International Education Studies, vol. 8, no. 4, pp. 111-121, 2015.

[6] V.P.J. Runtu, Eksplorasi Pengetahuan Matematika Masyarakat dalam Perancangan dan Implementasi Rancangan Tugas Tematik di Kabupaten Sangihe. Laporan penelitian Disertasi Doktor. Lembaga Penelitian Unima, 2016.

[7] S.O. Bekoe, L. Eshun and A. Bordoh, "Formative Assessment Techniques Tutors use to Assess Teacher-Trainees' Learning in Social Studies in Colleges of Education in Ghana," Research on Humanities and Social Sciences, vol. 3, no. 4, pp. 20-30, 2013.

[8] O.P. Ajaja and O.U. Eravwoke, "Effects of Cooperative Learning Strategy on Junior Secondary School Students Achievement in Integrated Science, Journal of Science Education, vol. 4, no. 1, pp. 2-18, 2010

[9] S. Uzun, N. Alev and I.S. Karal, "Cross-Age Study of an Understanding of Light and Sight Concepts in Physics," Science Education International, vol. 24, no. 2, pp. 129-149, 2013.

[10] M. Kazempour, "I can't teach science! A case study of an elementary pre-service teacher's intersection of science experiences, beliefs, attitude, and self-efficacy,". International Journal of Environmental and Science Education,vol. 9, no. 1, pp. 77-96, 2014.

[11] F. Favilli, "Ethnomathematics and mathematics education," Proceedings of the 10th International Congress of Mathematics Education Copenhagen, 2014.

[12] J.A. Bishop, "The Symbolic Technology Calet Mathematics its Role in Education", De Belgique: Bulletin De La Societe Mathematique. T, XLIII, 1991.

[13] J.A. Bishop, "Cultural Conflicts in the Mathematics Education of Indigenous People", Clyton, Viktoria: Monash University, 1994.

[14] P. Clanché, and B. Sarrazy, "Occurrence of typical cultural behavior in an arithmetic lesson: how to cope? In Favilli $\mathrm{F}$ (editor): ethnomathematics and mathematics education" - Proceedings of the 10th International Congress of Mathematics Education, 2014.

[15] J. Boaler, "Promoting 'relational equity' and high mathematics achievement through an innovative mixed ability approach," British Educational Research Journal, vol. 34, no. 2, pp. 167-194, 2008.

[16] W.S. Bush, "Improving Research on Mathematics Learning and Teaching in Rural Contexts", Journal of Research in Rural Education. Vol. 20, no. 8, 2005.

[17] F. Favilli and S. Tintori, Intercultural mathematical education: Comments about a didactic proposal. Proceedings of the 10 th International Congress on Mathematical Education, 2014.

[18] L. Hodge, Q. Zhao, J. Visnovska and P. Cobb, "What does it mean for an instructional task to be effective?," In J. Watson \& K. Beswick (Eds.), Mathematics: Essential Research, Essential Practice, vol. 1, pp. 329-401), 2017. 
[19] J. Ainley, D. Pratt, and A. Hansen, "Connecting engagement and focus in pedagogic task design". British Educational Research Journal, vol. 32, no. 1, pp. 23-38, 2006.

[20] T. Mandang and P.V.J. Runtu, Integrasi Konsep dengan Konteks Lokal dan Global dalam Pembelajaran Sains-Matematika di Kabupaten Sangihe. Laporan Penelitian Hibah Bersaing Tahun 2015, 2015.

[21] G. Anthony and M. Walshaw, "Characteristics of Effective Teaching of Mathematics: A View from the West," Journal of Mathematics Education, vol. 2, no. 2, pp. 147-164, 2009.
[22] P. Cobb and L.L. Hodge, "A relational perspective on issues of cultural diversity and equity as they play out in the mathematics classroom," Mathematical Thinking and Learning, vol. 4, pp. 249-284, 2002.

[23] A. Watson and J. Mason, "Seeing an exercise as a single mathematical object: Using variation to structure sense-making," Mathematical Thinking and Learning, vol. 8, pp. 91-111, 2006. 